\title{
Surface thermodynamic homeostasis of salivary conditioning films through polar-apolar layering
}

\author{
Henny C. van der Mei • Don J. White • \\ Jelly Atema-Smit • Gésinda I. Geertsema-Doornbusch • \\ Henk J. Busscher
}

Received: 12 August 2010 / Accepted: 18 January 2011 /Published online: 2 February 2011

(C) The Author(s) 2011. This article is published with open access at Springerlink.com

\begin{abstract}
Salivary conditioning films (SCFs) form on all surfaces exposed to the oral cavity and control diverse oral surface phenomena. Oral chemotherapeutics and dietary components present perturbations to SCFs. Here we determine the surface energetics of SCFs through contact angle measurements with various liquids on SCFs following perturbations with a variety of chemotherapeutics as well as after renewed SCF formation. Sixteen-hour SCFs on polished enamel surfaces were treated with a variety of chemotherapeutics, including toothpastes and mouthrinses. After treatment with chemotherapeutics, a SCF was applied again for $3 \mathrm{~h}$. Contact angles with four different liquids on untreated and treated SCF-coated enamel surfaces were measured and surface free energies were calculated. Perturbations either caused the SCF to become more polar or more apolar, but in all cases, renewed SCF formation compensated these changes. Thus, a polar SCF attracts
\end{abstract}

H. C. van der Mei $(\bowtie) \cdot J$. Atema-Smit •

G. I. Geertsema-Doornbusch · H. J. Busscher

Department of Biomedical Engineering,

University Medical Center Groningen,

Antonius Deusinglaan 1,

9713 AV Groningen, The Netherlands

e-mail: h.c.van.der.mei@med.umcg.nl

H. C. van der Mei · J. Atema-Smit •

G. I. Geertsema-Doornbusch • H. J. Busscher

University of Groningen,

Antonius Deusinglaan 1,

9713 AV Groningen, The Netherlands

D. J. White

The Procter \& Gamble Company,

Mason, OH, USA different salivary proteins or adsorbs proteins in a different conformation to create a more apolar SCF surface after renewed SCF formation and vice versa for apolar SCFs. This polar-apolar layering in SCF formation presents a powerful mechanism in the oral cavity to maintain surface thermodynamic homeostasis - defining oral surface properties within a narrow, biological range and influencing chemotherapeutic strategies. Surface chemical changes brought about by dietary or chemotherapeutic perturbations to SCFs make it more polar or apolar, but new SCFs are rapidly formed compensating for changes in surface energetics.

Keywords Salivary protein adsorption - Surface free energy Acid-base interactions · Conditioning film formation - Contact angles · Oral microbiome

\section{Introduction}

Saliva is critical to human physiology. Without it, speech and swallowing are difficult if not impossible and we would find ourselves prone to various oral and systemic diseases. The glandular secretions, which constitute saliva, serve a variety of functions affecting lubrication, taste, the early stages of digestion, and the protection of soft and hard tissues against environmental insults $[1,2]$. The functional characteristics of saliva include effects of soluble inorganic components, soluble enzymes, antimicrobial peptides, and a variety of low molecular weight and macromolecular glycoproteins, contributing to the formation of so-called conditioning films $[3,4]$. These salivary conditioning films (SCFs) are known to form on all surfaces exposed to the oral cavity, 
and in addition to functional benefits for the host, SCFs constitute the interface at which the oral microbiome is acquired.

One important characteristic of SCFs is their influence on the thermodynamic properties of oral surfaces. Wu and Nancollas [5] have demonstrated that a relationship exists between surface free energy and kinetics of mineralization and demineralization of dental hard tissues. Likewise, it is generally known that the surface energy of teeth and other substrata influence the adhesion and growth of oral bacteria and development of a more complex oral microbiome [6]. In our laboratories, we have for 8 years been exploring the interaction chemistries of SCFs with both diet [7] and hygiene variations, including various chemistries applied in oral chemotherapeutics [8-10]. In this paper, we describe unique observations on the surface energetics of SCFs on oral hard tissues both before and after environmental perturbations. Results directly support that salivary conditioning films control surface homeostasis at the thermodynamic level.

\section{Materials and methods}

\section{Surface conditioning film formation and treatment}

SCFs were developed in a standardized fashion from reconstituted whole human saliva on enamel surfaces. Human whole saliva from 20 healthy volunteers, equally divided over both sexes (average age $30 \pm 8$ years) was collected into ice-chilled cups after stimulation of salivary flow by chewing Parafilm ${ }^{\circledR}$. The medical ethical committee approved collection of human saliva, and patients gave their informed consent. After the saliva was pooled and centrifuged at $12,000 \mathrm{~g}$ for $15 \mathrm{~min}$ at $4^{\circ} \mathrm{C}$, phenylmethylsulfonylfluoride was added to a final concentration of $1 \mathrm{mM}$ as a protease inhibitor. The solution was again centrifuged, dialyzed for $24 \mathrm{~h}$ at $4^{\circ} \mathrm{C}$ against demineralized water, and freeze-dried for storage in order to provide for a stock. Finally, a lyophilized stock was prepared by mixing freeze-dried material originating from a total of 21 of saliva. Reconstituted human whole saliva was prepared from the lyophilized stock by dissolution of $1.5 \mathrm{mg} / \mathrm{ml}$ in buffer $(2 \mathrm{mM}$ potassium phosphate, $1 \mathrm{mM} \mathrm{CaCl}_{2}, 50 \mathrm{mM} \mathrm{KCl}, \mathrm{pH} 6.8$ ). Note that recently, it has been shown that freeze-thawing does not alter a saliva which has been stored at $-80^{\circ} \mathrm{C}$ for a period of 6 months [11].

For substrates, bovine enamel blocks were sectioned, mounted, and polished to a $0.3-\mu \mathrm{m}$ mirror finish. In order to obtain enamel surfaces, without contamination from polishing, the final polishing step was done in a slurry of
$\mathrm{Al}_{2} \mathrm{O}_{3}$ particles $(0.05 \mu \mathrm{m})$ in water, after which they were sonicated in demineralized water in order to remove the $\mathrm{Al}_{2} \mathrm{O}_{3}$ particles. X-ray photoelectron spectroscopy (XPS) demonstrated no residual aluminium on such polished surfaces, nor an inexplicably high carbon content, while water contact angles on thus prepared enamel surfaces were consistent with literature values [12]. SCFs were applied to all enamel blocks by $16-\mathrm{h}$ immersion in reconstituted saliva at room temperature. SCF-coated enamel surfaces were treated with a variety of chemotherapeutics including toothpastes and mouthrinses (see Table 1), which acted as strong environmental perturbations to the surfaces. For treatments, $25 \% \mathrm{w} / \mathrm{w}$ toothpaste slurries in water (application time $60 \mathrm{~s}$ ) or full-strength mouthwashes (application time $30 \mathrm{~s}$ ) were used and samples were washed afterwards by twice dipping in water. A total of 25 formulations and 3 combinations of a toothpaste and mouthrinse were used with widely different chemical components, such as sodium fluoride, stannous fluoride, hexametaphosphate, pyrophosphate, triclosan, cetylpyridinium chloride, baking soda, sodium lauryl sulphate, poloxamer 407, and polyvinyl methylether maleic acid (see Table 1). Over the years, the untreated SCF was measured multiple times and two averages, over the first and second half of the experimental 8-year period, were employed as separate data points, while a fluoridated toothpaste frequently used as a control (Crest Cavity Protection) was included as three data points. Two commercial mouthrinses were also used twice.

The key feature of these treatments for the context of this paper is their ability to perturb the baseline hydrophobicity of SCFs to either the hydrophilic or hydrophobic side. Six to ten enamel blocks were treated with the same chemotherapeutic and subsequent to treatment, half of the blocks were directly measured for surface free energy changes, while the other half of the blocks were exposed again to reconstituted saliva for $3 \mathrm{~h}$, prior to surface free energy assessment.

Surface free energy assessment through contact angle measurements

Surface free energies are best determined through a series of contact angles with different liquids, as can only be measured on SCFs that have been dried under rigorously controlled and constant conditions. To this end, contact angles with water on the SCF-coated enamel surfaces were measured after air drying to a so called "plateau level" of constant surface dryness [13], as monitored by water contact angle measurements over time. As soon as a plateau level of constant surface dryness was achieved, contact angles were also measured with a second polar liquid (formamide) and two apolar liquids (diiodomethane and $\alpha$-bromonaphthalene). Contact angles were measured in 
Table 1 Toothpastes (TP) and mouthrinses (MR) evaluated together with their main active components and manufacturer

\begin{tabular}{|c|c|c|c|}
\hline Product & Main active components & Manufacturer & Reference \\
\hline \multicolumn{4}{|l|}{ Commercial available toothpaste } \\
\hline Crest cavity protection & Sodium fluoride, SLS & Procter \& Gamble, Cincinnati, USA & [7] \\
\hline Crest vivid white & $\begin{array}{l}\text { Sodium fluoride, sodium } \\
\text { hexametaphosphate, poloxamer }\end{array}$ & Procter \& Gamble, Cincinnati, USA & \\
\hline Crest pro health & $\begin{array}{l}\text { Stannous fluoride, sodium } \\
\text { hexametaphosphate, SLS }\end{array}$ & Procter \& Gamble, Cincinnati, USA & \\
\hline Crest tartar protection & $\begin{array}{l}\text { Sodium fluoride, pyrophosphate, } \\
\text { SLS }\end{array}$ & Procter \& Gamble, Cincinnati, USA & \\
\hline Crest baking soda & $\begin{array}{l}\text { Sodium fluoride, sodium bicarbonate, } \\
\text { SLS }\end{array}$ & Procter \& Gamble, Cincinnati, USA & \\
\hline Crest gum care & Stannous fluoride, SLS & Procter \& Gamble, Cincinnati, USA & {$[7]$} \\
\hline Crest clean mint & Sodium fluoride, SLS & Procter \& Gamble, Cincinnati, USA & \\
\hline Crest multicare & Sodium fluoride, SLS & Procter \& Gamble, Cincinnati, USA & \\
\hline Colgate total ${ }^{\circledR}$ & $\begin{array}{l}\text { Triclosan, polyvinyl methylether } \\
\text { maleic acid, sodium fluoride, SLS }\end{array}$ & $\begin{array}{l}\text { Colgate-Palmolive Company, } \\
\text { Piscataway, USA }\end{array}$ & \\
\hline Mentadent baking soda & $\begin{array}{l}\text { Sodium fluoride, sodium bicarbonate, } \\
\text { hydrogen peroxide, poloxamer, SLS }\end{array}$ & $\begin{array}{l}\text { Church and Dwight Company, } \\
\text { Princeton, NJ, USA }\end{array}$ & \\
\hline Listerine & $\begin{array}{l}\text { Eucalyptol, menthol, methyl salicylate, } \\
\text { thymol, sodium monofluorphosphate, } \\
\text { SLS }\end{array}$ & $\begin{array}{l}\text { Warner-Lambert Consumer Healthcare, } \\
\text { Morris Plains, USA }\end{array}$ & \\
\hline Blendamed & Sodium fluoride, SLS & Procter \& Gamble, Cincinnati, Ohio, USA & \\
\hline \multicolumn{4}{|l|}{ Experimental toothpastes } \\
\hline Experimental TP I & $\begin{array}{l}\text { Sodium fluoride, SLS, surface } \\
\text { conditioners }\end{array}$ & & \\
\hline Experimental TP II & $\begin{array}{l}\text { Sodium fluoride, SLS, surface } \\
\text { conditioners }\end{array}$ & & \\
\hline Experimental TP III & $\begin{array}{l}\text { Sodium fluoride, SLS, surface } \\
\text { conditioners }\end{array}$ & & \\
\hline Experimental TP IV & $\begin{array}{l}\text { Sodium fluoride, SLS, surface } \\
\text { conditioners }\end{array}$ & & \\
\hline Experimental TP V & Stannous chloride, sodium fluoride, SLS & & \\
\hline Experimental TP VI & $\begin{array}{l}\text { Sodium fluoride, sodium } \\
\text { hexametaphosphate, SLS }\end{array}$ & & \\
\hline Experimental TP VII & $\begin{array}{l}\text { Sodium fluoride, SLS, surface } \\
\text { conditioners }\end{array}$ & & \\
\hline Experimental TP VIII & $\begin{array}{l}\text { Sodium fluoride, SLS, surface } \\
\text { conditioners }\end{array}$ & & \\
\hline \multicolumn{4}{|l|}{ Commercially available mouthrinses } \\
\hline Scope & Cetylpyridinium chloride & Procter \& Gamble, Cincinnati, USA & [9] \\
\hline Viadent & Cetylpyridinium chloride & $\begin{array}{l}\text { Colgate Oral Pharmaceuticals Inc., Canton, } \\
\text { USA }\end{array}$ & {$[9]$} \\
\hline \multicolumn{4}{|l|}{ Experimental mouthrinses } \\
\hline Experimental MR I & Cetylpyridinium chloride & & \\
\hline Experimental MR II & Cetylpyridinium chloride & & \\
\hline Experimental MR III & Surface conditioner & & \\
\hline \multicolumn{4}{|l|}{ Combined toothpaste and mouthrinse } \\
\hline Crest cavity protection + Scope & See above & See above & \\
\hline Crest cavity protection + Viadent & See above & See above & \\
\hline $\begin{array}{l}\text { Crest cavity protection }+ \text { Crest pro } \\
\text { health }\end{array}$ & See above & See above & \\
\hline
\end{tabular}

triplicate with a camera-goniometer system on three to five differently prepared enamel blocks, immediately after treatment with an oral health care product and after subsequent SCF formation.
The total SCF surface free energy and its Lifshitz-Van der Waals $\left(\gamma_{\mathrm{s}}^{\mathrm{LW}}\right)$, acid-base $\left(\gamma_{\mathrm{s}}^{\mathrm{AB}}\right)$ components along with its electron acceptor $\left(\gamma_{\mathrm{s}}^{+}\right)$and electron donor $\left(\gamma_{\mathrm{s}}^{-}\right)$parameters were subsequently calculated according to the 
Lifshitz-Van der Waals/acid-base (LW-AB) approach [14] by solving the matrix presented in Eq. 1 and using the standard liquid properties [15]

$$
\begin{aligned}
& {\left[\begin{array}{ccc}
\sqrt{\gamma_{\text {water }}^{\mathrm{LW}}} & \sqrt{\gamma_{\text {water }}^{+}} & \sqrt{\gamma_{\text {water }}^{-}} \\
\sqrt{\gamma_{\text {formamide }}^{\mathrm{LW}}} & \sqrt{\gamma_{\text {formamide }}^{+}} & \sqrt{\gamma_{\text {formamide }}^{-}} \\
\sqrt{\gamma_{\text {diiodomethane }}^{\mathrm{LW}}} & \sqrt{\gamma_{\text {diiodomethane }}^{+}} & \sqrt{\gamma_{\text {diiodomethane }}^{-}}
\end{array}\right]\left[\begin{array}{c}
\sqrt{\gamma_{\mathrm{s}}^{\mathrm{LW}}} \\
\sqrt{\gamma_{\mathrm{s}}^{-}} \\
\sqrt{\gamma_{\mathrm{s}}^{+}}
\end{array}\right]} \\
& =\left[\begin{array}{c}
\left(1+\cos \theta_{\text {water }}\right) \times \gamma_{\text {water }} / 2 \\
\left(1+\cos \theta_{\text {formamide }}\right) \times \gamma_{\text {formamide }} / 2 \\
\left(1+\cos \theta_{\text {diiodomethane }}\right) \times \gamma_{\text {diiodomethane }} / 2
\end{array}\right]
\end{aligned}
$$

in which $\gamma^{\mathrm{LW}}, \gamma^{+}$, and $\gamma^{-}$are Lifshitz-Van der Waals, electronaccepting, and electron-donating surface free energies of the various liquids (see subscripts), $\gamma_{\mathrm{s}}$ is the surface free energy of the solid surface, and $\theta$ is the measured contact angle (see subscripts for liquid). Note that whereas Eq. 1 is set up for the use of diiodomethane as an apolar liquid, an analogue equation can be set up for $\alpha$-bromonaphthalene. Since the use of different apolar liquids, may yield two slightly different outcomes in Lifshitz-Van der Waals surface free energy component $\left(\gamma_{\mathrm{s}}^{\mathrm{LW}}\right)$, all values for $\gamma_{\mathrm{s}}^{\mathrm{LW}}$ represent the average outcome for both apolar liquids.

X-ray photoelectron spectroscopy and thickness calculation

In addition to surface free energy, the amount of adsorbed material in SCFs was estimated from their dehydrated film thicknesses using an X-ray photoelectron spectrometer (S-Probe spectrometer; Surface Science Instruments, Mountain View, CA, USA) equipped with an aluminium anode $(10 \mathrm{kV}, 22 \mathrm{~mA})$ and a quartz monochromator. XPS was conducted at a photoelectron collection angle of $55^{\circ}$ with the sample and an electron flood gun setting of $10 \mathrm{eV}$. Elemental compositions were also calculated from overall scans in the binding energy range of $1-1,100 \mathrm{eV}$ with a $1,000 \times 250-\mu \mathrm{m}$ spot and a pass energy of $150 \mathrm{eV}$ accounting for instrumental sensitivity factors. The thickness of the SCFs was calculated using an overlayer model based upon the attenuation of the $\mathrm{Ca}_{2 \mathrm{p}}$ signal [16]. The XPS analyses were done on three separately prepared enamel blocks per treatment.

\section{Results}

The Lifshitz-Van der Waals surface free energy component $\gamma_{\mathrm{s}}^{\mathrm{LW}}$ of 16-h-old SCFs on enamel surfaces measures $36 \mathrm{~mJ} / \mathrm{m}^{2}$. Treatment with topical chemotherapeutics produced variable responses ranging from a reduction of $\gamma_{\mathrm{s}}^{\mathrm{LW}}$ to almost $25 \mathrm{~mJ} / \mathrm{m}^{2}$, to an increase to nearly $43 \mathrm{~mJ} / \mathrm{m}^{2}$ (Fig. 1).

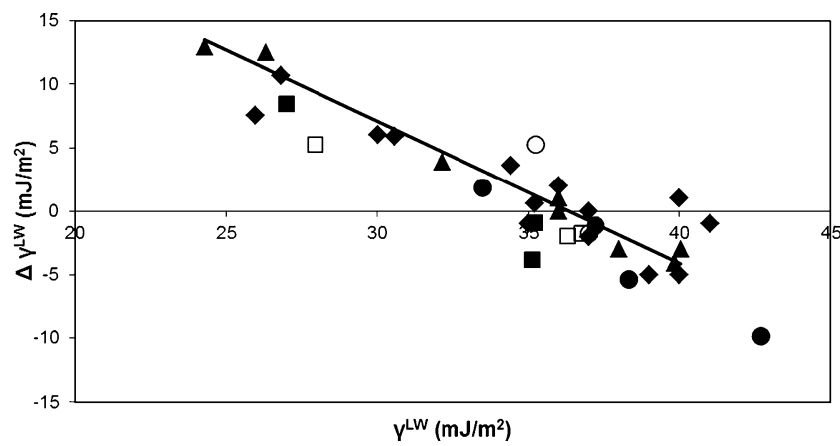

Fig. 1 The change in Lifshitz-Van der Waals surface free energy components $\Delta \gamma_{\mathrm{s}}^{\mathrm{LW}}$ of SCFs with and without exposure to a toothpaste slurry or mouthrinse upon renewed exposure to saliva as a function of its Lifshitz-Van der Waals surface free energy component $\gamma_{\mathrm{s}}^{\mathrm{LW}}$ immediately after treatment with a toothpaste slurry or mouthrinse. All data points represent measurements over three separately prepared samples, with an average SD of $2.3 \mathrm{~mJ} / \mathrm{m}^{2}$. Linear correlation coefficient equals 0.91 . Symbols denote: empty circle, untreated SCF ("pellicle"); shaded diamond, commercially available toothpastes; shaded triangle, experimental toothpastes; shaded circle, commercially available mouthrinses; empty square, experimental mouthrinses; shaded square, exposure to a toothpaste slurry followed by a mouthrinse treatment

Renewed SCF formation, however, yielded a positive change in $\gamma_{\mathrm{s}}^{\mathrm{LW}}$ when treatment caused a reduction, while vice versa for treatments that had caused an increase in $\gamma_{\mathrm{s}}^{\mathrm{LW}}$. Thus, SCF formation after treatment with surface active oral chemotherapeutic proceeds to compensate for any changes brought about in $\gamma_{\mathrm{s}}^{\mathrm{LW}}$. As can also be seen in Fig. 1, treated SCFs with a $\gamma_{\mathrm{s}}^{\mathrm{LW}}$ of $36 \mathrm{~mJ} / \mathrm{m}^{2}$ remain essentially unaffected by renewed SCF formation.

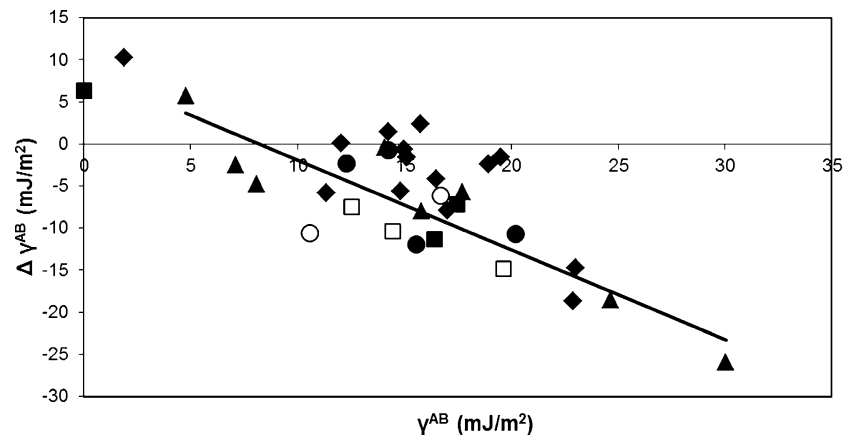

Fig. 2 The change in acid-base surface free energy components $\Delta \gamma_{\mathrm{s}}^{\mathrm{AB}}$ of SCFs with and without exposure to a toothpaste slurry or mouthrinse upon renewed exposure to saliva as a function of the SCF acid-base surface free energy component $\gamma_{\mathrm{S}}^{\mathrm{AB}}$ immediately after exposure to a toothpaste slurry or mouthrinse. All data points represent measurements over three separately prepared samples, with an average SD of $3.4 \mathrm{~mJ} / \mathrm{m}^{2}$. Linear correlation coefficient equals 0.79. Symbols denote: empty circle, untreated SCF ("pellicle"); shaded diamond, commercially available toothpastes; shaded triangle, experimental toothpastes; shaded circle, commercially available mouthrinses; empty square, experimental mouthrinses; shaded square, exposure to a toothpaste slurry followed by a mouthrinse treatment 

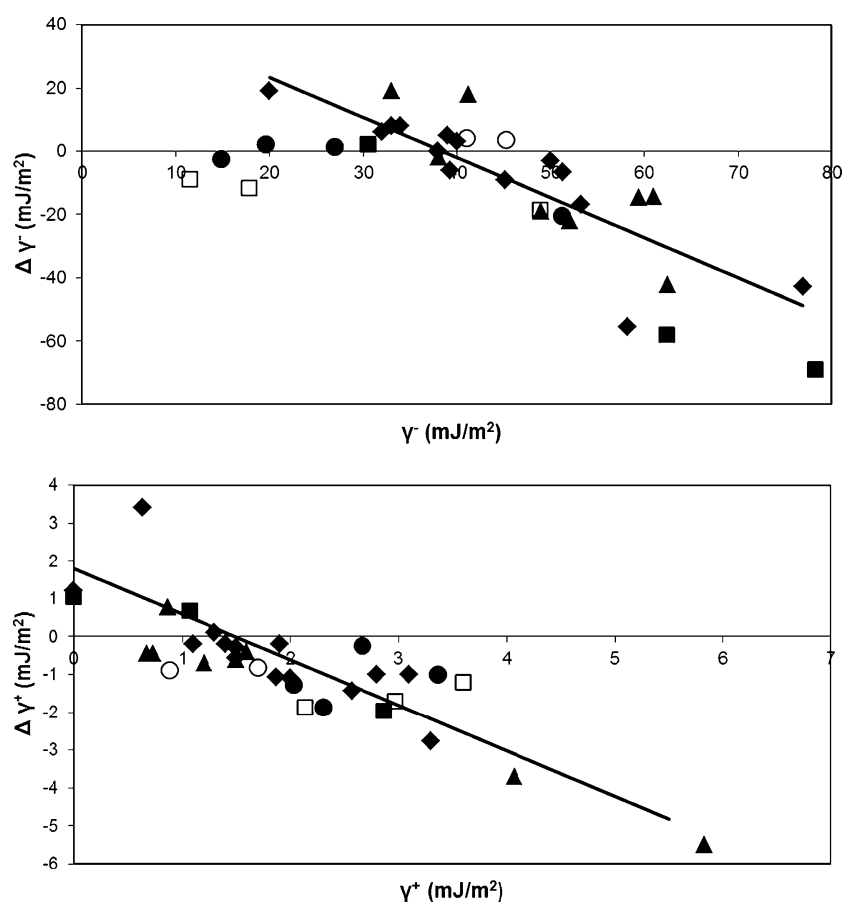

Fig. 3 The changes in electron-donating $\Delta \gamma_{\mathrm{s}}^{-}$(top) and electronaccepting $\Delta \gamma_{\mathrm{s}}^{+}$(bottom) surface free energy parameters of SCFs with and without exposure to a toothpaste slurry or mouthrinse upon renewed exposure to saliva as a function of the SCF surface free energy parameters $\gamma_{\mathrm{s}}^{-}$and $\gamma_{\mathrm{s}}^{+}$immediately after exposure to a toothpaste slurry or mouthrinse. All data points represent measurements over three separately prepared samples, with an average SD of 6.9 and $0.6 \mathrm{~mJ} / \mathrm{m}^{2}$ for the electron-donating and accepting parameters, respectively. Linear correlation coefficients equal 0.83 and 0.73 , for electron-donating and accepting parameters, respectively. Symbols denote: empty circle, untreated SCF ("pellicle"); shaded diamond, commercially available toothpastes; shaded triangle, experimental toothpastes; shaded circle, commercially available mouthrinses; empty square, experimental mouthrinses; shaded square, exposure to a toothpaste slurry followed by a mouthrinse treatment

Figures 2 and 3 present similar data for the acid-base surface free energy component $\gamma_{\mathrm{s}}^{\mathrm{AB}}$ (Fig. 2) and its electrondonating $\gamma_{\mathrm{s}}^{-}$and electron-accepting $\gamma_{\mathrm{s}}^{+}$parameters (Fig. 3). $\gamma_{\mathrm{s}}^{\mathrm{AB}}, \gamma_{\mathrm{s}}^{-}$, and $\gamma_{\mathrm{s}}^{+}$of untreated SCFs amount 14.0, 43.1, and $1.3 \mathrm{~mJ} / \mathrm{m}^{2}$, respectively and from Figs. 2 and 3, it can be seen that SCFs with corresponding values of $8.9,31.0$, and $1.2 \mathrm{~mJ} / \mathrm{m}^{2}$ remain unaffected by renewed SCF formation after treatment. Note again that these values are close to those observed for untreated SCFs.

The dehydrated thickness of SCFs on enamel surface in vacuo as determined by XPS amounts to $3.2 \mathrm{~nm}$. The detergent action of most oral health care product causes a decrease in the dehydrated SCF thickness (Fig. 4) primarily due to surfactancy effects, although in some cases, adsorption of components in oral chemotherapeutics causes an increase in the SCF thickness. In all cases, however, continued SCF formation tends to converge its dehydrated thickness to a value of $2.9 \mathrm{~nm}$. Note that thickness data were not available for all formulations.

\section{Discussion}

The oral cavity undergoes tremendous environmental perturbations on a daily basis. Overnight, salivary excretion decreases significantly, and we sometimes awake to sensorially objectionable dry tissues. With each meal, hard and soft tissues are exposed to a variety of soluble fats, proteins, carbohydrates [7], and divergent ionic strengths and pHs. In addition to these diurnal perturbations, oral hygiene presents strong perturbations to surface equilibria in the oral cavity. Oral chemotherapeutics are de facto designed for surface cleansing and conditioning, and thus to cause major perturbations to SCFs. In this study, we see that perturbation of a SCF can cause changes in its LifshitzVan der Waals, and most notably, in its acid-base surface free energy component. Environmental challenges, including those from oral chemotherapeutics can either cause the SCF to become more polar or more apolar, but importantly in all cases, renewed SCF formation compensates for these changes at the thermodynamic level, resulting in a surface energetic state that closely resembles the one of an untreated SCF. This recovery, which we call polar-apolar layering due to the involvement of acid-base interactions, is remarkable, considering the fact that even minute changes on a surface, like a carbonaceous monolayer contaminating glass surfaces, can yield a tremendous change in surface free energy. Under the influences of saliva, a SCF that has become more polar upon perturbation appeared to attract

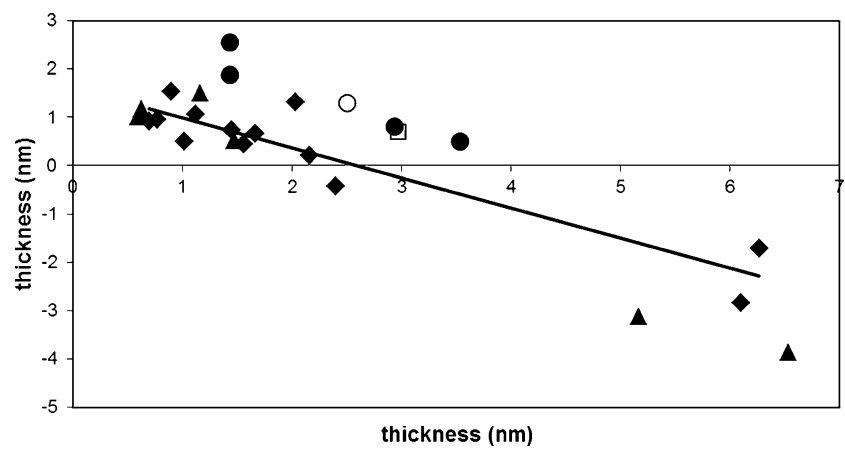

Fig. 4 The change $(\Delta)$ in dehydrated SCF thickness with and without exposure to a toothpaste slurry or mouthrinse upon renewed exposure to saliva as a function of the SCF thickness immediately after exposure to a toothpaste slurry or mouthrinse. All data points represent measurements over three separately prepared samples, with an average SD of $0.6 \mathrm{~nm}$. Linear correlation coefficient equals 0.85 . Symbols denote: empty circle, untreated SCF ("pellicle"); shaded diamond, commercially available toothpastes; shaded triangle, experimental toothpastes; shaded circle, commercially available mouthrinses; empty square, experimental mouthrinses; shaded square, exposure to a toothpaste slurry followed by a mouthrinse treatment 
salivary components whose adsorption yielded a more apolar SCF surface after renewed SCF formation and vice versa for perturbations producing apolar SCFs. The relationships between surface energetics of SCFs after chemotherapeutic exposure and changes in energetics following renewed SCF formation comprise a total of 25 different products and have been obtained over a period of 8 years. Yet, the relationships are convincing and without major outliers. In the past, it has been suggested that salivary protein formation converges the surface energy of different nonbiological substratum surfaces in the oral cavity [17], but this has never been shown for salivary conditioning film formation on a treated biological film as the SCF. Moreover, by virtue of the LW-AB analysis of measured contact angles, the role of acid-base interactions in renewed SCF formation on treated SCFs has become clear here. Interestingly, polar-apolar layering after chemotherapeutical perturbation occurs without an increase in dehydrated layer thickness as observed by XPS (see Fig. 4), which is in agreement with results by Vassilakos et al. [18] using in situ by ellipsometry and demonstrating that secondary exposure of a treated SCF to saliva did not cause an increase in adsorbed SCF.

Surface chemical changes brought about by dietary or chemotherapeutic perturbations to SCFs in vivo have been assessed as well by clinical contact angle registration [19, 20]. However, clinical contact angles could not be measured with formamide, diiodomethane, and $\alpha$ bromonaphthalene due to their toxicity and hence no surface free energy analysis could be established. Nevertheless, water contact angles measured in vivo as a function of time after perturbation by toothbrusing or use of mouthrinses clearly showed that surface chemical effects in vivo were transient and nearly always disappeared within $24 \mathrm{~h}$, depending on the chemotherapeutic treatment $[9,19$, 20]. This suggests that recovery of SCFs through polarapolar layering after chemotherapeutic challenge occurs in vivo too.

Salivary conditioning films are derived in large part from proteins adsorbed from saliva. Saliva contains a myriad of macromolecules ranging in size from low molecular weight cationic charged histatins [21, 22] to mucin glycoproteins $(100-1,000 \mathrm{kd})[2,23-25]$. The proteins in saliva exhibit profound multifunctionality, but are thought to contribute primarily to the lubrication and coating of tissues [24]. Of course, another important aspect of salivary proteins is the change in their properties and functions in solution as compared with those when adsorbed [26]. Upon adsorption to a surface, the arrival of proteins in flatland [27] may stimulate unfolding, depending on the properties of the surface and the protein involved. So-called soft proteins are more apt to unfolding than hard proteins, while the stability of the folded conformation may depend on ionic strength.
It appears from the current study, that acid-base interactions primarily drive the polarity of a SCF. Following environmental perturbations, new films are rapidly formed compensating for changes in surface energetics. This process of polar-apolar layering yields an intriguing equilibrium that is somewhat at odds with the "ordered" process of SCF acquisition and formation in unperturbed systems [28]. While the exact chemical nature of the compensating adsorption has yet to be determined, it may include readsorption of macromolecules through different conformational changes or through layered selective secondary adsorption [29]. Indeed, elemental surface analysis by XPS confirms that nitrogen, representing adsorbed proteins, plays a pivotal role in polar-apolar layering and it tends to achieve a stable value of around $8.3 \% N$. For example, a treated SCF with a $\gamma_{\mathrm{s}}^{\mathrm{LW}}$ of $42.7 \mathrm{~mJ} / \mathrm{m}^{2}$ possesses a $\gamma_{\mathrm{s}}^{\mathrm{LW}}$ of $32.9 \mathrm{~mJ} / \mathrm{m}^{2}$ after $3 \mathrm{~h}$ of additional SCF formation, concurrent with an increase in the $\% N$ from $7.2 \%$ to $9.8 \%$. Analogously, a treated SCF with a $\gamma_{\mathrm{s}}^{\mathrm{LW}}$ of $24.3 \mathrm{~mJ} / \mathrm{m}^{2}$ that changed to $\gamma_{\mathrm{s}}^{\mathrm{LW}}$ of $37.3 \mathrm{~mJ} / \mathrm{m}^{2}$ after $3 \mathrm{~h} \mathrm{SCF}$ formation experienced a concurrent increase in the $\% N$ from $1.3 \%$ to about the same stable value $8.6 \%$. From these two examples, it can be concluded that thermodynamic homeostasis is in agreement with the chemical homeostasis.

While previous studies have documented that SCFs are variably removed and redeposited with oral hygiene measures, including chemotherapeutic treatment [30], this study is the first to assess effects of these processes in a thermodynamic context. It is paradoxical that the thrust toward development of oral chemotherapeutics is often directed at conditioning film modifications [31], while it now becomes obvious why many of these techniques show only modest clinical effects or require repeated applications to produce therapeutic changes. Though confounding the best intentions of clinicians and researchers attempting to "control" the oral surfaces to reduce disease risks, the redundancy and balancing effects of salivary proteins on SCF energetics yield a homeostasis that keeps the SCF energetics close to the equilibrium likely established in our early ancestors, lacking the heavy perturbations of our current oral chemotherapeutics. Likewise, the results help to explain the robust homeostasis observed within the oral environment, including the microbiome that populates the oral habitat. It would be of interest to explore whether variations exist in SCF energetics in different populations or in populations with different dietary regimes to see if local or even evolutionary changes are observed. Recently, Perry et al. [32] found that the copy number of the salivary amylase gene (AMY1) is correlated positively with salivary amylase protein levels and that individuals from populations with high starch diets have, on average, more $A M Y 1$ copies than populations consuming less starch. This example of positive selection on a copy number variable gene was positioned by Perry and coworkers as one of the first discovered within the human 
genome. It is also well known that human diets with higher proportions of refined sugar result in the selective adaptation of oral microbiomes to contain more acidogenic, tooth decay causing, species like Streptococcus mutans [33]. The polarapolar layering in SCF formation observed here has never been described before and could explain how the oral cavity manages to maintain surface thermodynamics within a narrow, biological range, despite environmental challenges including diet.

Acknowledgment This study was supported by Proctor \& Gamble, Mason, OH, USA, and by the University Medical Center GroningenUniversity of Groningen, Groningen, The Netherlands.

Conflict of interest The authors declare that they have no conflict of interest.

Open Access This article is distributed under the terms of the Creative Commons Attribution Noncommercial License which permits any noncommercial use, distribution, and reproduction in any medium, provided the original author(s) and source are credited.

\section{References}

1. Dawes C (2008) Salivary flow patterns and the health of hard and soft oral tissues. J Am Dent Assoc 139(Supp):18S-24S

2. Tabak LA (1995) In defense of the oral cavity: structure, biosynthesis, and function of salivary mucins. Annu Rev Physiol 57:547-564

3. Vigna D, de Almeida P, Trindade Grégio AM, Naval Machado MA, Soares de Lima AA, Reis Azevedo LR (2008) Saliva composition and functions: a comprehensive review. J Contemp Dent Pract 9:72-80

4. Lendenmann U, Grogan J, Oppenheim FG (2000) Saliva and dental pellicle - a review. Adv Dent Res 14:22-28

5. Wu W, Nancollas GH (1997) The relationship between surface freeenergy and kinetics in the mineralization and demineralization of dental hard tissue. Adv Dent Res 11:566-575

6. Quirynen M, Bollen CM (1995) The influence of surface roughness and surface-free energy on supra- and subgingival plaque formation in man. A review of the literature. J Clin Periodontol 22:1-14

7. Van der Mei HC, White DJ, Kamminga-Rasker HJ, Knight J, Baig AA, Smit J, Busscher HJ (2002) Influence of dentifrices and dietary components in saliva on wettability of pellicle-coated enamel in vitro and in vivo. Eur J Oral Sci 110:434-438

8. Busscher HJ, White DJ, Atema-Smit J, Van der Mei HC (2007) Efficacy and mechanisms of non-antibacterial, chemical plaque control by dentifrices - an in vitro study. J Dent 35:294-301

9. Busscher HJ, White DJ, Atema-Smit J, Geertsema-Doornbusch G, De Vries J, Van der Mei HC (2008) Surfactive and antibacterial activity of CPC formulations in vitro and in vivo. J Clin Periodontol 35:547-554

10. Van der Mei HC, Engels E, De Vries J, Busscher HJ (2008) Effects of aminefluoride on biofilm growth and salivary pellicles. Caries Res 42:19-27

11. Schipper R, Loof A, De Groot J, Harthoorn L, Dransfield E, Van Heerde W (2007) SELDI-TOF-MS of saliva: methodology and pretreatment effects. J Chromatogr 847:45-53

12. Perdok JF, Van der Mei HC, Genet MJ, Rouxhet PG, Busscher HJ (1989) Elemental surface concentration ratios and surface free energies of human enamel after application of chlorhexidine and adsorption of salivary constituents. Caries Res 23:297-302

13. Van Oss CJ, Gillman CF (1972) Phagocytosis as a surface phenomenon. J Reticuloendothel Soc 12:283-292

14. Van Oss CJ (1995) Hydrophobicity of biosurfaces - origin, quantitative determination and interaction energies. Colloids Surf B Biointerfaces 5:91-110

15. Good RJ, Van Oss CJ (1992) The modern theory of contact angles and the hydrogen bond components of surface free energies. In: Schrader ME, Loeb GI (eds) Modern approaches to wettability: theory and application. Plenum press, New York, pp 1-28

16. Busscher HJ, Van der Mei HC, Genet MJ, Perdok JF, Rouxhet PG (1990) XPS determination of the thickness of adsorbed mouthrinse components on dental enamel. Surf Interface Anal 15:344-346

17. Van Dijk LJ, Goldsweer R, Busscher HJ (1988) Interfacial free energy as a driving force for pellicle formation in the oral cavity: an in vivo study in Beagle dogs. Biofouling 1:19-25

18. Vassilakos N, Arnebrant T, Glantz PO (1993) An in vitro study of salivary film formation at solid/liquid interfaces. Scand J Dent Res 101:133-137

19. Van der Mei HC, Kamminga-Rasker HJ, De Vries J, Busscher HJ, White DJ, Date R, Day T, White CD, Williams MK (2003) The influence of a hexametaphosphate-containing chewing gum on the wetting ability of salivary conditioning films in vitro and in vivo. J Clin Dent 14:14-18

20. Busscher HJ, White DJ, Van der Mei HC, Baig AA, Kozak KM (2002) Hexametaphosphate effects on tooth surface conditioning film chemistry - in vitro and in vivo studies. J Clin Dent 13:38-43

21. De Smet K, Contreras R (2005) Human antimicrobial peptides: defensins, cathelicidins and histatins. Biotechnol Lett 27:13371347

22. Oppenheim FG, Xu T, McMillian FM, Levitz SM, Diamond RD, Offner GD, Troxler RF (1988) Histatins, a novel family of histidine-rich proteins in human parotid secretion. Isolation, characterization, primary structure, and fungistatic effects on Candida albicans. J Biol Chem 263:7472-7477

23. Tabak LA, Levine MJ, Mandel ID, Ellison SA (1982) Role of salivary mucins in the protection of the oral cavity. J Oral Pathol $11: 1-17$

24. Offner GD, Troxler RF (2000) Heterogeneity of high-molecularweight human salivary mucins. Adv Dent Res 14:69-75

25. Zalewska A, Zwierz K, Zółkowski K, Gindzieński A (2000) Structure and biosynthesis of human salivary mucins. Acta Biochim Pol 47:1067-1079

26. Lindh L (2002) On the adsorption behaviour of saliva and purified salivary proteins at solid/liquid interfaces. Swed Dent J Suppl $152: 1-57$

27. Norde W (2008) My voyage of discovery to proteins in flatland... and beyond. Colloids Surf B Biointerfaces 61:1-9

28. Hannig M, Joiner A (2006) The structure, function and properties of the acquired pellicle. Monogr Oral Sci 9:29-64

29. Vroman L (2008) Finding seconds count after contact with blood (and that is all I did). Colloids Surf B Biointerfaces 62:1-4

30. Joiner A, Swarz A, Philpotts CJ, Cox TF, Huber K, Hannig M (2008) The protective nature of pellicle towards toothpaste abrasion on enamel and dentine. J Dent 36:360-368

31. Guan YH, Lath DL, Graaf T, Lilley TH, Brook AH (2003) Moderation of oral bacterial adhesion on saliva-coated hydroxyapatite by polyasparate. J Appl Microbiol 94:456-461

32. Perry GH, Dominy NJ, Claw KG, Lee AS, Fiegler H, Redon R, Werner J, Villanea FA, Mountain JL, Misra R, Carter NP, Lee C, Stone AC (2007) Diet and the evolution of human amylase gene copy number variation. Nat Genet 39:1256-1260

33. Carlsson J (1989) Microbial aspects of frequent intake of products with high sugar concentrations. Scand J Dent Res 97:110-114 